University of South Carolina

Scholar Commons

1985

\title{
Using Parameter Estimation Techniques with a Simple Model of a Diaphragm-Type Electrolyzer to Predict the Electrical Energy Cost for $\mathrm{NaOH}$ Production
}

John Van Zee

University of South Carolina - Columbia, vanzee@engr.sc.edu

Ralph E. White

University of South Carolina - Columbia, white@cec.sc.edu

Follow this and additional works at: https://scholarcommons.sc.edu/eche_facpub

Part of the Chemical Engineering Commons

\section{Publication Info}

Journal of the Electrochemical Society, 1985, pages 818-826.

(c) The Electrochemical Society, Inc. 1985. All rights reserved. Except as provided under U.S. copyright law, this work may not be reproduced, resold, distributed, or modified without the express permission of The Electrochemical Society (ECS). The archival version of this work was published in Journal of the

Electrochemical Society.

http://www.electrochem.org/

Publisher's Version: http://dx.doi.org/10.1149/1.2113965

DOI: $10.1149 / 1.2113965$

This Article is brought to you by the Chemical Engineering, Department of at Scholar Commons. It has been accepted for inclusion in Faculty Publications by an authorized administrator of Scholar Commons. For more information, please contact digres@mailbox.sc.edu. 
REFERENCES

1. A. J. Schrijner and A. Middelhoek, This Journal, 111, 1167 (1964).

2. J. J. Randall, Electrochim. Acta, 20, 663 (1975).

3. C. J. Dell'Oca and L. Young, This Journal, 117, 1545 (1970).

4. C. J. Dell'Oca and L. Young, ibid. 11\%, 1548 (1970).

5. F. J. Burger and J. C. Wu, ibid., 118, 2039 (1971).

6. J. M. Albella, I. Montero, and J. M. Martinez-Duart, ibid., 131, 1101 (1984)

7. S. Ikonopisov, Electrochim. Acta, 22, 1077 (1977).

8. J. J. Randall, W. J. Bernard, and R. R. Wilkinson, ibid., 10, 183 (1965).
9. S. Hofmann and J. M. Sanz, J. Trace Microprobe Technol., 1, 213 (1982).

10. J. M. Albella, I. Montero, and J. M. Martínez-Duart, Thin Solid Films, 58, 307 (1979).

11. G. Amsel, C. Cherki, G. Feuillade, and J. P. Nadai, J. Phys. Chem. Solids, 30, 2117 (1969).

12. I. Montero, J. M. Albella, and J. M. Martinez-Duart, This Journal, 132, 976 (1985)

13. L. Young, ibid., 124, 528 (1977).

14. J. G. Simmons, Phys. Rev., 155, 657 (1967).

15. P. L. Young, J. Appl. Phys., 47, 235 (1976).

16. S. Ikonopisov, Electrochim. Acta, 14,761 (1969).

17. V. Kadary and N. Klein, This Journal, 127, 139 (1980).

\title{
Using Parameter Estimation Techniques with a Simple Model of a Diaphragm-Type Electrolyzer to Predict the Electrical Energy Cost for $\mathrm{NaOH}$ Production
}

\author{
John Van Zee* \\ Department of Chemical Engineering, University of South Carolina, Columbia, South Carolina 29208
}

R. E. White*

Department of Chemical Engineering, Texas A\&M University, College Station, Texas 77843

\begin{abstract}
Predictions of the electrical energy cost for $\mathrm{NaOH}$ production are determined as a function of the independent operating variables and diaphragm characterizing properties. The predictions are based on data from a statistically designed experiment, a simple model of a diaphragm-type electrolyzer, a simple model of the cell voltage losses, and parameter estimation techniques. The data were obtained over a sufficiently large range of operating conditions so that the resulting design equation may be industrially useful. The simple model of the diaphragm is based on the mass transport of the hydroxyl ion, a linear potential gradient, and is presented in terms of measurable diaphragm properties. These properties are the thickness of the diaphragm $(t)$ and a resistivity-ratio, $\rho / \rho_{0}$, where $\rho$ is the resistivity of the diaphragm filled with electrolyte and $\rho_{0}$ is the resistivity of the electrolyte (this ratio may come to be known as the MacMullin number, $N_{\mathrm{M}}$ ). It is shown that, according to the model of the cell, the caustic yield or current efficiency of the diaphragm cell depends on the product of $N_{\mathrm{M}}$ and $t$ and not on each separately. The simple model of the cell voltage considers the diaphragm voltage drop, anode and cathode kinetics, and the bubble-filled brine-gap voltage drop. Parameter estimation techniques are used to determine the best values of the diffusion coefficient, average specific conductivity, exchange current densities, and transfer coefficients; these parameters and the simple models provide a design equation for the electrical energy cost of $\mathrm{NaOH}$ production using a diaphragm cell. The design equation is used to predict a minimum electrical-energy cost at a particular $N_{\mathrm{M}} t$.
\end{abstract}

In a diaphragm-type chlorine/caustic cell (see Fig.1), hydroxyl ions are produced at the cathode according to the electrochemical reaction

$$
\mathrm{H}_{2} \mathrm{O}+e^{-} \rightarrow \mathrm{OH}^{-}+\frac{1}{2} \mathrm{H}_{2}
$$

The energy cost for the production of hydroxyl ions depends upon the diaphragm characteristics and the operating conditions of current density and percolation velocity. That is, to prevent the loss of $\mathrm{OH}^{-}$ions due to migration and diffusion, cell electrolyte percolates through the diaphragm from the anolyte as shown in Fig. 1. This percolation rate must not be too large, however, because the concentration of $\mathrm{OH}^{-}$in the catholyte decreases as the percolation rate increases, which leads to a larger steam requirement if the catholyte is to be concentrated to the typical $50 \%$ by weight solution. Increasing the current density increases the concentration of $\mathrm{OH}^{-}$ions in the catholyte, but also increases the voltage drop through the diaphragm, which increases the electrical energy cost. Also, the diaphragm characteristics affect the diffusion and migration of hydroxyl ion and the voltage drop through the diaphragm. It is desirable, therefore, to have a simple model which is consistent with industrial production cells and which can be used to predict the con-

* Electrochemical Society Active Member. centration of $\mathrm{OH}^{-}$ions in the catholyte and the diaphragm voltage drop as a function of the percolation velocity, current density, and diaphragm characterizing properties. It is also desirable to combine this simple diaphragm model with a simple model of the cell voltage losses which include the thermodynamics, kinetics, and ohmic losses so that predictions of the electrical energy cost for $\mathrm{NaOH}$ production can be made. (A more quantitative definition of electrical energy cost is given below in the "Energy Cost" section).

These predictions are highly dependent on the transport and kinetic parameters used in the model. Consequently, it is necessary to use a set of parameters which (i) is consistent with experimental data over a large range of operating conditions and (ii) has reasonably small confidence intervals for the parameters. Here, we use the theory of nonlinear least squares regression (1-4) to obtain a suitable set of parameters for a simple model. In this sense, we do not test various models to determine the most reasonable, but, rather, we assume that the simple model presented here is reasonable and then determine the parameters which give the "best fit" of the data. In the same sense, it is not the purpose of this paper to compare the model predictions with experimental data that were not used to obtain the parameters. [See Lee (5) for a general discussion of the use of parameter estimation in electrochemical reactor design.] 


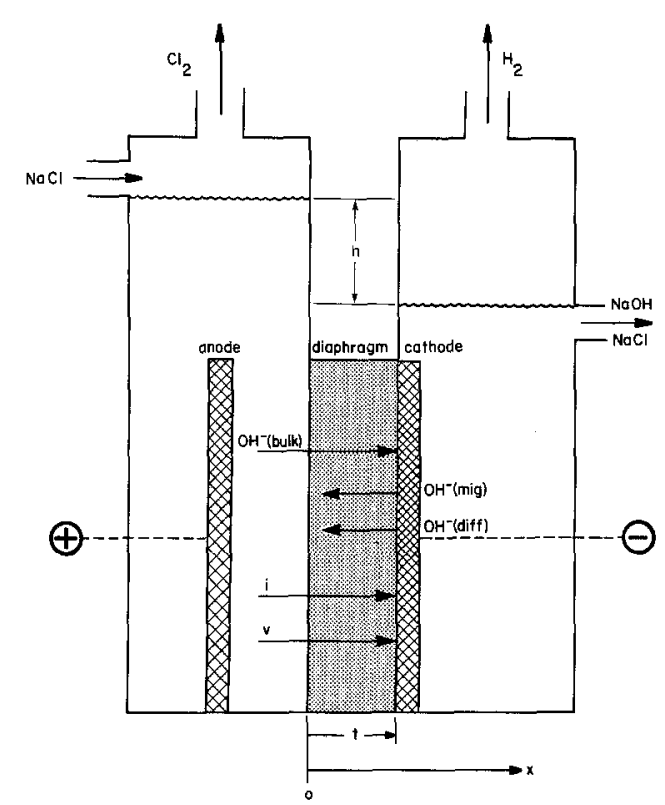

Fig. 1. A diaphrogm-type chlorine/coustic cell schematic

Simple models of the diaphragm ${ }^{1}$ have been presented before (6-10), but none have included measurable diaphragm properties as independent variables, which is required for the determination of diaphragm-independent transport parameters by regression. Also, none of the previous workers have shown the effects of these diaphragm properties and the operating conditions on the energy cost for the production of $\mathrm{NaOH}$ in a diaphragm-type electrolyzer. Consequently, the diaphragm characterizing properties used here will be discussed, and the previously published models will be reviewed. Then, a simple model of the diaphragm-type chlorine/caustic cell which considers $\mathrm{OH}^{-}$ion only will be developed and discussed in terms of dimensionless groups. The model then will be compared in more detail to previously published models and then to experimental data using nonlinear regression to estimate the transport and kinetic parameters. Finally, predictions of the electrical energy cost per metric ton of $\mathrm{NaOH}$ will be discussed as a function of the independent diaphragm properties and operating conditions.

\section{Literature Review}

In a recently reported, factorially designed experiment (11), two quantities were used to characterize the diaphragm in a metal anode chlorine $/ \mathrm{NaOH}$ electrolyzer. These two properties are the MacMullin number, $N_{\mathrm{M}}$, and the diaphragm thickness, $t$. The MacMullin number is defined $(12,13)$ as follows

$$
N_{\mathrm{M}}=\frac{\tau}{\epsilon}=\frac{\rho}{\rho_{\mathrm{o}}}
$$

where $\rho / \rho_{0}$ is the ratio of the electrical resistivity of an electrolyte-saturated porous medium to the resistivity of the same thickness of electrolyte. An experimental procedure is available for measuring independently both the MacMullin number and the thickness of a diaphragm (11). It should be noted that $N_{\mathrm{M}}$ has also been referred to as the formation factor (14) and the labyrinth factor (15).

Of the simple models of the diaphragm that have been proposed $(6-10)$, only Koh $(9,10)$ and Mukaibo (7) included diaphragm characterizing properties, but neither recognized that $N_{\mathrm{M}}$ can be measured directly from relatively simple experiments. Koh $(9,10)$ used a diaphragm characterizing parameter which was obtained from an assumed value for $\tau$ or the product $\tau$ and a presumably measured value for $\epsilon$. Mukaibo (7) [see also Hine $(14,16,17)$ ] used the ratio of the diaphragm area to the area of the dia-

${ }^{1}$ Throughout this paper, the phrase "simple model of the diaphragm" is used to indicate a model with a linear potential graphragm" is used to indicate a modytical integration of the governing differential equations. phragm pores, which is not measurable directly, and, hence, this ratio was an assumed quantity when the model was compared with experimental data (16). The often-used model of Stender et al. (6) does not include a parameter such as $N_{\mathrm{M}}$, but some recent modifications of this model $(17,18)$ have recognized the need to include diaphragm properties which are independent of the transport parameters; again, these recent modifications use assumed values for $\epsilon$ or $\tau$, and therefore they cannot be used to determine the best values of the transport parameters for use with the model. Kubasov et al. (19) include the thickness of the diaphragm multipled by a "sinuosity coefficient" as the characterizing parameter, but this coefficient was not reported as a measurable quantity.

In addition to the lack of measurable diaphragm properties, other differences exist between the previously published diaphragm models and the model presented here. For example, Gallone and Rubino (8) neglected the effect of ionic migration. Hine $(14,16,17)$ does not show the difference between the solution conductivity and the effective solution conductivity in the diaphragm. Mukaibo (7) assumed that the ratio of the transference number to the concentration of hydroxyl ion is constant throughout the diaphragm.

Also, the model presented here differs from the previously reported models in the specification of the boundary condition at the catholyte/diaphragm interface. That is, the model of Stender et al. (6), for example, is developed with a physically unrealistic boundary condition, a fixed catholyte concentration. Consideration of Fig. 1 reveals that the concentration in the catholyte depends on the velocity and the current density as well as the diaphragm properties and therefore cannot be specified $a$ priori as an independent, fixed quantity. Thus, Stender's expression for the concentration profile of hydroxyl ion $\{\mathrm{Eq}[13]$ in Ref. (6)\} does not show the correct dependence on velocity and current density because it includes the concentration at the interface.

The previously reported simple diaphragm models (6-10) have not been used to analyze the combined effects of diaphragm properties and operating conditions on the energy cost for $\mathrm{NaOH}$ production. That is, although Koh $(9,10)$ showed the effect of his diaphragm effectiveness parameter on electrolyzer energy consumption, the interaction between current density, velocity, and diaphragm properties (e.g., $N_{\mathrm{M}}$ and $t$ ) was not discussed. The contribution of the diaphragm voltage drop to energy cost and the effect of diaphragm parameters on the voltage drop were not discussed by Koh or the authors of the other simple models. Hine (14) showed diaphragm IR data for a stagnant laboratory-scale diaphragm cell, but comparison of this data to model predictions was not reported. Also, the contributions of electrode kinetics to the energy consumption have not been reported previously but are included here. A more complicated model (12) of chlorine/ $\mathrm{NaOH}$ metal anode electrolyzer has shown the effect of the product of $N_{\mathrm{M}}$ and $t$ on specific energy consumption; however, only the essence of the model was presented, and the details were avoided for proprietary reasons.

\section{Model}

The assumptions of the simple models are as follows.

1. Dilute solution theory (20) applies.

2. The hydroxyl ion is the only species of interest within the diaphragm, and all reactions of $\mathrm{OH}^{-}$with other species (e.g., $\mathrm{H}^{+}$and $\mathrm{Cl}_{2}$ ) occur at the anolyte/diaphragm interface. (This assumption is reasonable because the concentrations of the other species in the diaphragm are relatively small, on the order of $2 \%$ of that of the $\mathrm{OH}^{-}$ ion.)

3. The spatial dimension in the direction parallel to the velocity (see Fig. 1) is the only important dimension for material balances.

4. The effective diffusion coefficient for hydroxyl ion in the porous diaphragm can be written in terms of the MacMullin number (12) 


$$
D_{\mathrm{e}}=\frac{D_{1}}{N_{\mathrm{M}}}
$$

5. The current density through the diaphragm is simply related to the potential gradient through the diaphragm by an effective average specific conductivity

$$
i=-\frac{\kappa_{\mathrm{avg}}}{N_{\mathrm{M}}} \frac{d \Phi}{d x}
$$

6. Water vapor loss from the catholyte is negligible, and the generated $\mathrm{H}_{2}$ gas mixes the catholyte so that the hydroxyl ion concentration at the diaphragm/catholyte interface equals the hydroxyl ion concentration in the electrolyzer effluent.

7. The electrochemical kinetics at the anode and cathode can be approximated by a Tafel approximation

$$
\Delta V_{\mathrm{kin,i}}=\frac{R T}{\alpha_{\mathrm{i}} \mathbf{F}} \ln \left|\frac{i}{i_{0, \mathbf{i}}}\right|
$$

where $i=1$ and 2 for cathode and anode, respectively.

8. The effect of temperature on $\Delta U^{\theta}$ is negligible.

9. The Nernst concentration correction to the opencircuit or thermodynamic voltage of the electrolyzer is negligible.

10. The voltage drop between the anode and the diaphragm is given by

$$
\Delta V_{\text {anolyte }}=\frac{i s}{\left(1-\epsilon_{\mathrm{b}}\right)^{1.5} \kappa_{\text {anolyte }}}
$$

where $\left(1-\epsilon_{b}\right)^{1.5}$ is the Bruggeman correction for the effect of bubbles in the anolyte $(21,22)$ and $\epsilon_{b}$ is assumed to be independent of current density.

With these assumptions, the steady-state material balance for hydroxyl ion in the diaphragm is

$$
\frac{d N_{1}}{d x}=0
$$

where the expression for the flux of hydroxyl ion in the porous diaphragm can be written (12) as

$$
N_{1}=-\frac{D_{1}}{N_{M}} \frac{d C_{1}}{d x}+\frac{D_{1}}{N_{M}} \frac{\mathbf{F}}{R T} C_{1} \frac{d \Phi}{d x}+v C_{1}
$$

The boundary conditions can be obtained from the second and sixth assumptions above and by recognizing that the anolyte and catholyte approximate completely mixed reactors. That is, for a typical anolyte $\mathrm{pH}$ of 2 , the $\mathrm{OH}^{-}$ concentration is

$$
\text { at } x=0, \quad C_{1}=0
$$

Since $\mathrm{OH}^{-}$is produced at the diaphragm/catholyte interface, and since the flux in the catholyte chamber consists of only convection (i.e., $v C_{k}$ ), the material balance is

$$
\text { at } x=t \quad N_{1}(x=t)+\frac{i}{\mathbf{F}}=v C_{1}(x=t)
$$

Substituting Eq. [4] into Eq. [8] yields

$$
N_{1}=-\frac{D_{1}}{N_{\mathrm{M}}} \frac{d \mathbf{C}_{1}}{d x}-\frac{D_{1}}{\kappa_{\mathrm{avg}}} \frac{\mathbf{F} i}{R T} \mathrm{C}_{1}+v \mathbf{C}_{1}
$$

Substituting Eq. [11] into Eq. [7] yields the second-order differential equation which governs the concentration of hydroxyl ion throughout the diaphragm

$$
\frac{D_{1}}{N_{\mathrm{M}}} \frac{d^{2} C_{1}}{d x^{2}}+\left(\frac{D_{1} \mathbf{F} i}{\kappa_{\mathrm{avg}} R T}-v\right) \frac{d C_{1}}{d x}=0
$$

Integration of Eq. [12] subject to the boundary conditions (Eq. [9] and [10]) is readily accomplished [see Ref. (23), for example], and the result can be written as

$$
C_{1}(x)=\frac{\frac{i}{v \bar{F}}\left\{1-\exp \left(A_{1} x\right)\right\}}{\left[\frac{\mathbf{F} i D_{1}}{R T \kappa_{\mathrm{avg}} v}-\exp \left(A_{1} t\right)\right]}
$$

where

$$
A_{1}=\left(\frac{-\mathbf{F} i N_{\mathrm{M}}}{R T \kappa_{\mathrm{avg}}}+\frac{v N_{\mathrm{M}}}{D_{1}}\right)
$$

Equation [13] is plotted in Fig. 12 and 13 of Ref. (23) and can be used to obtain an expression for the hydroxyl ion concentration in the effluent

$$
C_{1}(t)=\frac{\frac{i}{v \mathbf{F}}\left\{1-\exp \left(A_{1} t\right)\right\}}{\left[\frac{\mathbf{F} i D_{1}}{R T \kappa_{\mathrm{avg}} v}-\exp \left(A_{1} t\right)\right]}
$$

Equation [14] shows that the effluent concentration is a dependent variable when the velocity and current density are considered independent variables. An expression for the caustic yield, $\eta$, can be obtained by using the following definition

$$
\eta=\frac{v C_{1, \text { effluent }}}{i / \mathbf{F}}=\frac{v C_{1}(t) \mathbf{F}}{i}
$$

where by the sixth assumption above, $C_{1, \text { effluent }}=C_{1}(t)$.

Substituting Eq. [14] into Eq. [15] yields

$$
\eta=\frac{\left\{1-\exp \left(A_{1} t\right)\right\}}{\left\{\frac{\mathrm{F} i D_{1}}{R T \kappa_{\mathrm{avg}} v}-\exp \left(A_{1} t\right)\right\}}
$$

Note that Eq. [14] and [16] show that $C_{1}(t)$ and $\eta$ depend on the product of $N_{\mathrm{M}}$ and $t$ and not on either quantity separately. This should be expected, since $N_{\mathrm{M}} t$ is simply the effective thickness of the diaphragm. Also, it should be emphasized that $\eta$ is a derived quantity, not a parameter. That is, $\eta$ is calculated according to Eq. [15] after the governing equation for $C_{1}(x)$ (Eq. [12]) has been solved subject to the boundary conditions (Eq. [9] and [10]). Also, note that none of Eq. [7]-[12] contain $\eta$ and that this is different from the formation of Caldwell et al. (12) and Stender et al. (6).

\section{Energy Cost}

The specific electrolyzer energy cost for $\mathrm{NaOH}, \mathrm{EC}_{\mathrm{el}}$, can be formulated as the ratio of the energy consumption rate to the mass production rate of $\mathrm{NaOH}$ multiplied by the electrical energy cost, $\mathrm{CE}$

$$
\mathrm{EC}_{\mathrm{el}}=\frac{i V_{\mathrm{T}}}{M_{1} C_{1}(t) v} \mathrm{CE}
$$

In Eq. [17], the current density, $i$, and the velocity, $v$, are considered as independent variables, while $C_{1}(t)$ is deter-

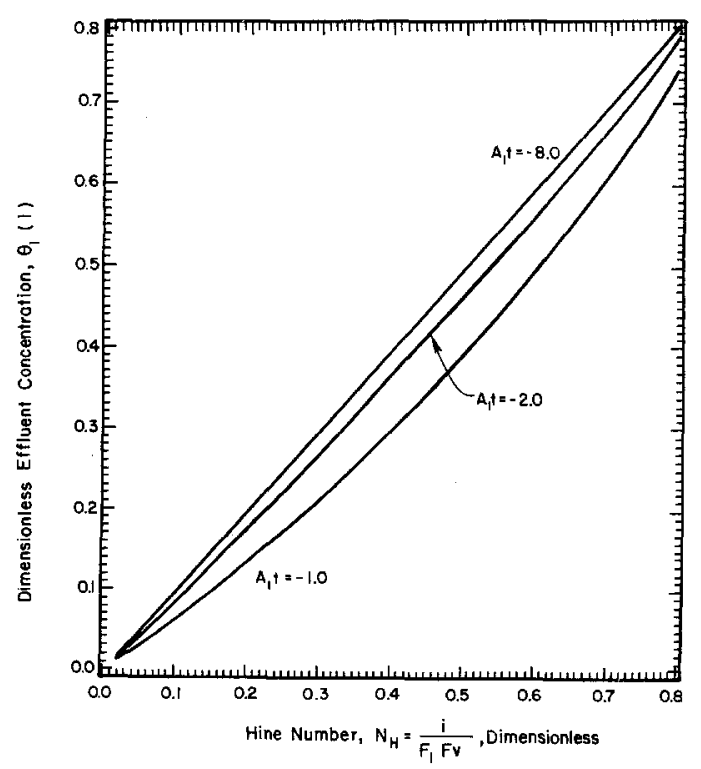

Fig. 2. Effluent concentration dependence on $A_{1} t$ and $N_{H}$. 
mined by Eq. [14] as a dependent variable. Also, the sum of the cell voltage drops, $V_{T}$, is a dependent variable and includes the kinetic voltage drops at each electrode, the thermodynamic voltage required for the sum of the cathodic and anodic reactions, the voltage drop in the anolyte, and the diaphragm voltage drop. The diaphragm is typically deposited onto the cathode and, hence, any voltage drop in the catholyte is negligible. Using the fifth and seventh through tenth assumptions above gives

$$
\begin{aligned}
V_{\mathrm{T}}=\frac{i N_{\mathrm{M}} t}{\kappa_{\mathrm{avg}}}+\frac{R T}{\mathbf{F}}\left[\left(\frac{1}{\alpha_{1}}\right.\right. & \left.\left.+\frac{1}{\alpha_{2}}\right) \ln |i|-\frac{\ln \left(i_{0,1}\right)}{\alpha_{1}}-\frac{\ln \left(i_{0,2}\right)}{\alpha_{2}}\right] \\
& +\left|\Delta U^{\theta}\right|+\frac{i s}{\left(1-\epsilon_{\mathrm{b}}\right)^{1.5} \kappa_{\text {anolyte }}}
\end{aligned}
$$

\section{Other Dimensionless Groups}

It is, perhaps, worth mentioning that dimensionless groups other than the ones shown in Eq. [16] can be formulated. For example, Eq. [16] can be rewritten as

$$
\eta=\frac{1-\exp (\mathrm{Pe}+\Delta \phi)}{\frac{-\Delta \phi}{\mathrm{Pe}}-\exp (\mathrm{Pe}+\Delta \phi)}
$$

where $\mathrm{Pe}$ is the Peclet number

$$
\mathrm{Pe}=\frac{v N_{\mathrm{M}} t}{D_{1}}
$$

and $-\Delta \phi$ is the dimensionless diaphragm IR drop

$$
-\Delta \phi=-\frac{\mathbf{F}}{R T}[\Phi(x=t)-\Phi(x=0)]=\frac{\mathbf{F} i N_{\mathrm{M}} t}{R T \kappa_{\mathrm{avg}}}
$$

The Peclet number is a measure of the effect of convection relative to diffusion and is used routinely by chemical engineers. The dimensionless diaphragm IR drop, $-\Delta \phi$, can be thought of as a measure of the importance of the effect of ionic migration.

These dimensionless groups can also be used to write in dimensionless form an expression for the concentration distribution for $\mathrm{OH}^{-}$ions

$$
\theta_{1}(\zeta)=\frac{C_{1}(x)}{F_{1}}=\frac{N_{\mathrm{H}}\{1-\exp [(\mathrm{Pe}+\Delta \phi) \xi]\}}{\frac{-\Delta \phi}{\mathrm{Pe}}-\exp (\mathrm{Pe}+\Delta \phi)}
$$

where $F_{1}$ is the concentration of the $\mathrm{NaCl}$ in the brine feed (a constant) and $N_{\mathrm{H}}$ is the Hine number defined as

$$
N_{\mathrm{H}}=\frac{i}{\mathbf{F} F_{1} v}
$$

since Hine and Yasuda (24) were apparently the first to recognize the significance of $i / \mathbf{F} v$.

\section{Comparison of Diaphragm Model to Existing Models}

Expressions similar to those given above for $C_{1}(x), C_{1}(t)$, and $\eta$ have been presented by Stender et al. (6), Koh (9), and Mukaibo (7) which with modifications or definitions of effective thickness can be shown to be consistent with the model presented here. The expressions presented by Stender et al. (6) for $C_{\mathrm{l}}(x)$ and $\eta$ are not correct because they do not contain $N_{M}$ or a similar quantity. Their equations are written in terms of $\delta$ (defined to be the thickness of the diaphragm), but their expression for $\eta$ can be seen to be equivalent to Eq. [16] by defining $\delta$ in terms of measurable diaphragm properties

$$
\delta=N_{\mathrm{M}} t
$$

Thus, their $\delta$ should be the effective thickness and not the measured diaphragm thickness. Using Eq. [24], their dimensionless parameter $U \delta / D_{1}$ can be shown to be equal to $A_{1} t$ of Eq. [13], [14], and [16]. In addition, their equation for $C_{1}(x)$ is not complete because it depends on the concentration of $\mathrm{OH}^{-}$in the catholyte, which also depends on other variables in their expression for $\mathrm{C}_{\mathrm{OH}}-(x)$. That is, for example, both $v$ and $C_{1}(t)$ cannot be set while holding $i$ fixed because only two independent operating variables exist for the isothermal case. This point is easily overlooked when $C_{1}(x)$ is made dimensionless by $C_{1}(t)$ and the resulting expression (i.e., divide Eq. [13] by Eq. [14]) is graphed as a function of distance, $x$, as is shown by Hine et al. [14] in their Fig. 12. The resulting expression, and hence Fig. 12 of Ref. (14), appears as a function of only one dimensionless variable, $U \delta / D_{1}$, which is misleading because the dimensionless concentration profile is described by three dimensionless groups (divide both sides of Eq. [13] by $F_{1}$ or see Eq. [22]). Furthermore, if $C_{1}(t) / F_{1}$ is held constant, then $i / v \mathbf{F} F_{1}$ must be changed as $\mathrm{A}_{1} t$ is changed; this point is illustrated in Fig. 2, which shows that $C_{1}(t) / F_{1}$ depends on both $A_{1} t$ and $i / v \mathbf{F} F_{1}$. Two exceptions to this dependence occur as follows

$$
\begin{array}{cc}
A_{1} t<-20 ; & C_{1}(t)=\frac{R T \kappa_{\mathrm{avg}}}{\mathbf{F}^{2} D_{1}} \\
A_{1} t>20 ; & C_{1}(t)=\frac{i}{v \mathbf{F}}
\end{array}
$$

Also, when $A_{1} t=0$, Eq. [13], [14], and [16] become indeterminate forms because the quantity $\mathbf{F} i D_{1} / R T \kappa_{\text {avg }} v$ equals 1.0. For these indeterminate forms, application of l'Hopital's rule results in the following limit

$$
C_{1}(x)=\frac{1.0}{\left(\frac{D_{1} \mathbf{F}}{i N_{M} t}+\frac{v \mathbf{F}}{i}\right)}
$$

when

$$
A_{1} t=0
$$

Next, consider the equation for $\eta$ presented by Koh (9). His equation for $\eta$ contains a length parameter, EL, which can be shown to be equal to $N_{\mathrm{M}}$ t by considering Koh's definition of EL

$$
\mathrm{EL}=\nu / \epsilon
$$

and the definitions of $l$ (average pore length) and $N_{M}$ (12)

$$
\begin{gathered}
l=\tau t \\
N_{M}=\tau / \epsilon
\end{gathered}
$$

where $\tau$ is the tortuosity and $\epsilon$ is the porosity of the diaphragm. ${ }^{2}$ Substitution of Eq. [29] and [30] into Eq. [28] shows that

$$
\mathrm{EL}=N_{\mathrm{M}} t
$$

However, even though Koh's equation for $\eta$ does contain an effective thickness parameter, he did not recognize that it can be determined by measuring $N_{\mathrm{M}}$ and $t$. Instead, he used an assumed value for $\tau$ and a presumably measured value for $\epsilon$ to obtain $N_{\mathrm{M}} t$ (his EL). Unfortunately, his $N_{\mathrm{M}} t$ values are scaled for proprietary reasons, and his equation for $\eta$ is difficult to use because it contains a parameter (his $A$ ) which is incorrect as written.

Mukaibo's $(6,16)$ expression for $\eta$ is also similar to Eq. [16]; however, his equation is based on a different approach. He defined a transference number for $\mathrm{OH}^{-}$as follows

$$
n_{1}=\frac{t_{1}(x)}{C_{1}(x)}
$$

and assumed that $n_{1}\left(\operatorname{not} t_{1}\right)$ is constant throughout the diaphragm. He then defined the flux of $\mathrm{OH}^{-}$through the diaphragm to be

$$
N_{1}=\frac{-D_{1}}{A_{1} / A_{p}} \frac{d C_{1}}{d x}-n_{1} C_{1} \frac{i}{\mathbf{F}}+v C_{1}
$$

and integrated Eq. [7] with $N_{1}$ given by Eq. [33] in a man-

${ }^{2}$ Actually, Caldwell et al. (12) define $N_{\mathrm{M}}$ as $\tau^{2} / \epsilon$, but it is immaterial whether $\tau$ is squared or not, since it is not a quantity that can be measured directly. 
ner similar to that shown in Ref. (23). The equations he obtained for $C_{1}(t)$ and $\eta$ do have the correct dependence on $N_{\mathrm{M}}$, since $N_{\mathrm{M}}$ is related simply to his area ratio

$$
N_{\mathrm{M}}=A_{\mathrm{d}} / A_{\mathrm{p}}
$$

as can be seen by defining (10) the porosity of the diaphragm as

$$
\epsilon=l A_{\mathrm{p}} / t A_{\mathrm{d}}
$$

and using Eq. [29] and [30]

$$
N_{\mathrm{M}}=\tau / \epsilon=\frac{l}{t} \frac{A_{\mathrm{d}} / A_{\mathrm{p}}}{l / t}=\frac{A_{\mathrm{d}}}{A_{\mathrm{p}}}
$$

Even though Mukaibo presented equations that do have the correct dependence on $N_{\mathrm{M}}$, he did not recognize that $N_{\mathrm{M}}$ can be measured directly and he did not present an equation for $C_{1}(x)$. Also, his concept of a constant transference number $\left(n_{1}\right)$ is perhaps less appealing than the concept of a constant, average specific conductivity. This may be so because $\kappa_{\text {avg }}$ can be measured directly by assuming that $\kappa_{\text {avg }}$ is equal to the specific conductivity of an aqueous solution of $\mathrm{NaCl}$ and $\mathrm{NaOH}$ at their average concentrations over the range of effluent concentrations of interest (e.g., 2.5M of each), whereas $n_{1}$ cannot. However, it is interesting to note that an average value for $n_{1}$ can be obtained from $\kappa_{\text {avg }}$, if $D_{1}$ is known.

This can be seen by considering the definitions of $t_{1}$ and $\kappa$. That is, according to Newman (20), the transport number for species $\mathrm{j}$ in an electrolyte solution is given by

$$
t_{\mathrm{j}}=\frac{z_{\mathrm{j}}^{2} u_{\mathrm{j}} C_{\mathrm{j}}}{\sum_{\mathrm{i}} z_{\mathrm{i}}^{2} u_{\mathrm{i}} C_{\mathrm{i}}}
$$

and the specific conductivity is given by

$$
\kappa=\mathbf{F}^{2} \sum_{\mathrm{i}} z_{\mathrm{i}}^{2} u_{\mathrm{i}} \mathbf{C}_{\mathrm{i}}
$$

Substitution of Eq. [38] into Eq. [37] written for $\mathrm{OH}^{-}$ yields

$$
t_{1}=\frac{u_{1} C_{\mathbf{1}} \mathbf{F}^{2}}{\kappa}
$$

which, by assuming that the Nernst-Einstein equation (20) is valid

$$
u_{1}=\frac{D_{1}}{R T}
$$

shows that

$$
n_{1}=\frac{t_{1}}{C_{1}}=\frac{\mathbf{F}^{2} D_{1}}{R T \kappa}
$$

Thus, once values for $D_{1}$ and $\kappa_{\text {avg }}$ are known, an average value for $n_{1}$ could be calculated according to Eq. [41].

\section{Parameter Estimation}

Diaphragm model.-The diaphragm model presented above is formulated in terms of two transport properties of the electrolyte solution within the diaphragm, $D_{1}$ and $\kappa_{\text {avg. }}$. Both $D_{1}$ and $\kappa_{\text {avg }}$ are average quantities which depend on temperature and the average concentration within the diaphragm. Values for these average quantities are not available in the literature.

Their values can be estimated by nonlinear least squares (LS) regression of Eq. [14] or [16] against measured values of $C_{1}(t)$ or $\eta$, respectively. Note that $\eta$ is derived from a combination of dependent and independent variables. ${ }^{3}$ With this regression approach, the model is "fitted" to the data, and statistical theory (1-4) states that the estimates of $D_{1}$ and $\kappa_{\mathrm{avg}}$ are the best values for the data

${ }^{3}$ For the model presented here, $i$ and $v$ are considered independent variables and, hence, one should obtain the same estimates for $D_{1}$ and $\kappa_{\text {avg }}$ by using either $C_{1}(t)$ or $\eta$ as the dependent variable in the regression model. That is, statistical theory specifies that the independent variables are known precisely or at least within very small error limits (2) so that all of the error in $\eta$ can be attributed to $C_{1}(t)$. in the sense that the estimates result in the minimum difference between the observed and predicted values of $\eta$. Then the model with these estimates can be used for interpolation. Confidence is gained in the model if the parameter estimates obtained by LS are physically realistic. If the parameter estimates are physically realistic, extrapolations beyond the experimental range could be made within the limits of the assumptions of the model. Also, if the number of data points is large, confidence intervals on the parameter estimates can be obtained in the same manner as in linear regression (3).

The estimation of $D_{1}$ and $\kappa_{\mathrm{avg}}$ by LS requires experimental data in which both $N_{\mathrm{M}}$ and $t$ are measured quantities. The factorially designed experiments of Ref. (11) provide data in which $N_{\mathrm{M}}$ was varied from 3.3 to 7.5 and $t$ was varied from 0.17 to $0.33 \mathrm{~cm}$. Also, the current density and velocity were measured precisely and cell temperature was controlled at $70^{\circ} \pm 0.5^{\circ} \mathrm{C}$. In addition, the brine feed concentration was set with either a high or low acid and a constant salt concentration. The diaphragm voltage drop and the concentration of $\mathrm{OH}^{-}$ion in the effluent were measured simultaneously as dependent variables. Note that $D_{1}$ and $\kappa_{\mathrm{avs}}$ are independent of the diaphragm properties and, therefore, are free stream parameters rather than effective parameters of the particular diaphragm. Thus, by fixing the values of $N_{\mathrm{M}}$ and $t$ and the independent operating variables, $i$ and $v$, the only parameters of the model which can account for an inadequate model are the values of $D_{1}$ and $\kappa_{\text {avg. }}$.

It should be noted that the experimental cells of Ref. (11) consisted of laboratory cells which were designed by scaling down industrial-size electrolyzers so that geometric similarity was maintained. These cells contained a diaphragm which was placed in contact with a perforated steel cathode as shown in Fig. 1. The experimental cells were therefore consistent with the majority of industrial, metal anode cells which have the diaphragm vacuum deposited on the cathode.

Also, the model presented above was formulated to be consistent with the laboratory cells of Ref. (11). These cells were run for a period of 35 days. The replicate steady-state data were obtained over the entire period (26).

The predictions of the caustic yield and the diaphragm voltage drop are coupled through the average conductivity, $\kappa_{\text {avg }}$, and thus an appropriate LS objective function is

$$
G(\underline{\beta})=\sum_{1=1}^{N} \frac{\left(\eta_{1}^{0}-\eta_{1}^{p}\right)^{2}}{\hat{\sigma}_{1}{ }^{2}}+\sum_{\mathrm{k}=1}^{\mathrm{M}} \frac{\left(\Delta \Phi_{\mathrm{k}}{ }^{0}-\Delta \Phi_{\mathrm{k}}^{\mathrm{p}}\right)^{2}}{\hat{\sigma}_{2}{ }^{2}}
$$

where $\eta_{1}^{\mathrm{p}}$ is predicted by Eq. [16] at the experimental conditions corresponding to the $\mathrm{lth}$ datum, $\Delta \Phi_{\mathrm{k}}{ }^{\mathrm{p}}$ is predicted by integration of Eq. [4] at the experimental conditions corresponding to the $k$ th datum, and $\hat{\sigma}_{1}{ }^{2}$ and $\hat{\sigma}_{2}{ }^{2}$ correspond to the estimated variance of $\eta$ and $\Delta \Phi$, respectively.

The nonlinearity of Eq. [42] results from the nonlinear model equation for $\eta$, but it does not affect the theory behind LS regression $(3,4)$. The computations necessary to minimize this objective function become more complicated with a nonlinear function, but many computers have subroutine libraries which can perform the necessary calculations. In this work, minimization subroutines of the International Mathematical and Statistical Library (25) were used (26).

Each of the estimated variance $\left(\hat{\sigma}_{1}{ }^{2}\right.$ and $\left.\hat{\sigma}_{2}{ }^{2}\right)$ in Eq. [42] correspond to the sum of the variance associated with the measurement error and the variance associated with the model error. That is, we assume (in accordance with the assumptions of LS theory) any difference between the observed and predicted values is a lumped error which is distributed randomly. Thus, $\hat{\sigma}_{1}{ }^{2}$, for example, was calculated by dividing the minimum value of $G(\beta)$ when $\hat{\sigma}_{2}{ }^{2}=\infty$ by the degrees of freedom [in this case, $N-2$, since two parameters are adjusted to minimize $G(\beta)]$. Similarly, $\hat{\sigma}_{2}{ }^{2}$ was calculated by dividing the minimum value of $G(\hat{\beta})$ when $\hat{\sigma}_{1}{ }^{2}=\infty$ by $(M-1)$ (only one parameter, $\kappa_{\mathrm{avg}}$, is adjusted to minimize $G(\underline{\beta})$ when $\hat{\sigma}_{1}{ }^{2}=\infty$ ). 
Table I. Parameter estimates for diaphragm model

\begin{tabular}{|c|c|c|c|c|c|}
\hline \multicolumn{6}{|c|}{ Case A. Parameter estimates with $\hat{\sigma}_{2}{ }^{2}=\infty ; N=84$} \\
\hline Parameter & Estimate & \pm & $\begin{array}{l}95 \% \text { Confidence } \\
\text { interval }\end{array}$ & Units & $\stackrel{a}{t \text {-statistic }}$ \\
\hline $\begin{array}{l}D_{1} \\
\kappa_{\text {avg }} \\
\hat{\sigma}_{1}^{2}\end{array}$ & $\begin{array}{l}3.352 \times 10^{-5} \\
0.422 \\
1.118 \times 10^{-3}\end{array}$ & $\begin{array}{l} \pm \\
\pm\end{array}$ & $\begin{array}{l}0.275 \times 10^{-5} \\
0.060 \\
-\end{array}$ & $\begin{array}{c}\mathrm{cm}^{2} / \mathrm{s} \\
\Omega^{-1} \mathrm{~cm}^{-1} \\
\text { none }\end{array}$ & $\begin{array}{l}24.3 \\
14.7 \\
-\end{array}$ \\
\hline Parameter & Estimate & $\begin{array}{l}\text { Par } \\
\pm\end{array}$ & $\begin{array}{l}\text { tes with } \hat{\sigma}_{1}{ }^{2}=\infty ; 1 \\
95 \% \text { Confidence } \\
\text { interval }\end{array}$ & Units & $\frac{a}{t \text {-statistic }}$ \\
\hline $\begin{array}{l}\kappa_{\text {avg }} \\
\hat{\sigma}_{2}{ }^{2}\end{array}$ & $\begin{array}{l}0.3261 \\
2.688 \times 10^{-3}\end{array}$ & + & $\frac{0.0154}{-}$ & $\begin{array}{l}\Omega^{-1} \mathrm{~cm}^{-1} \\
\mathrm{~V}^{2}\end{array}$ & $\stackrel{42.3}{-}$ \\
\hline \multicolumn{3}{|c|}{ Case C. Parameter estimates with $\hat{\sigma}_{1}{ }^{2}=1.118 \times 10^{-3}$ and $\hat{\sigma}_{2}{ }^{2}=2.688 \times 10^{-3} \mathrm{~V}$} & $\begin{array}{l}1.118 \times 10^{-3} \text { and } \\
95 \% \text { Confidence } \\
\text { interval }\end{array}$ & $\begin{array}{l}{ }^{10^{-3} \mathrm{~V}} \\
\text { Units }\end{array}$ & $\frac{a}{t \text {-statistic }}$ \\
\hline $\begin{array}{l}D_{1} \\
\kappa_{\mathrm{avg}} \\
G(\beta)\end{array}$ & $\begin{array}{l}2.826 \times 10^{-5} \\
0.338 \\
1.627 \times 10^{-2}\end{array}$ & $\begin{array}{l} \pm \\
\pm\end{array}$ & $\begin{array}{l}0.112 \times 10^{-5} \\
0.016 \\
-\end{array}$ & $\begin{array}{c}\mathrm{cm}^{2} / \mathrm{s} \\
\Omega^{-1} \mathrm{~cm}^{-1} \\
\text { none }\end{array}$ & $\begin{array}{l}49.7 \\
41.6 \\
-\end{array}$ \\
\hline
\end{tabular}

a See Ref. (26).

The weighting of the dependent variables in the LS objective function in this fashion gives the "best values" of the parameters for Eq. [16] and [21] and the data (27). These estimated variances are shown in cases A and B of Table I. Note that $\hat{\sigma}_{1}$ is dimensionless, since $\eta$ is dimensionless, whereas $\hat{\sigma}_{2}$ has the dimensions of $\Delta \Phi$. The parameter estimates for $D_{1}$ and $\kappa_{\text {avg }}$ shown for cases $\mathrm{A}$ and $\mathrm{B}$ can be compared with the parameters of case $C$, which were estimated with the objective function weighted as described above. That is, including the data on the voltage drop through the diaphragm lowers the estimates of $D_{1}$ and $\kappa_{\text {avg }}$ and narrows the confidence intervals. The narrow confidence intervals indicate a greater sensitivity of the case $\mathrm{C}$ objective function to changes in the parameter values.

Figures 3 and 4 compare the predicted and observed values of $\eta$ and $\Delta \Phi$ at the estimates of case $C$ in Table $I$. The slopes and intercepts shown on Fig. 3 and 4 indicate that the diaphragm model agrees well enough with the experimental data to be useful for approximate design purposes. The large dispersion of observed voltage drops for a given predicted voltage drop may be a result of the fifth assumption made above; that is, the potential drop is probably a nonlinear function of the operating varia-

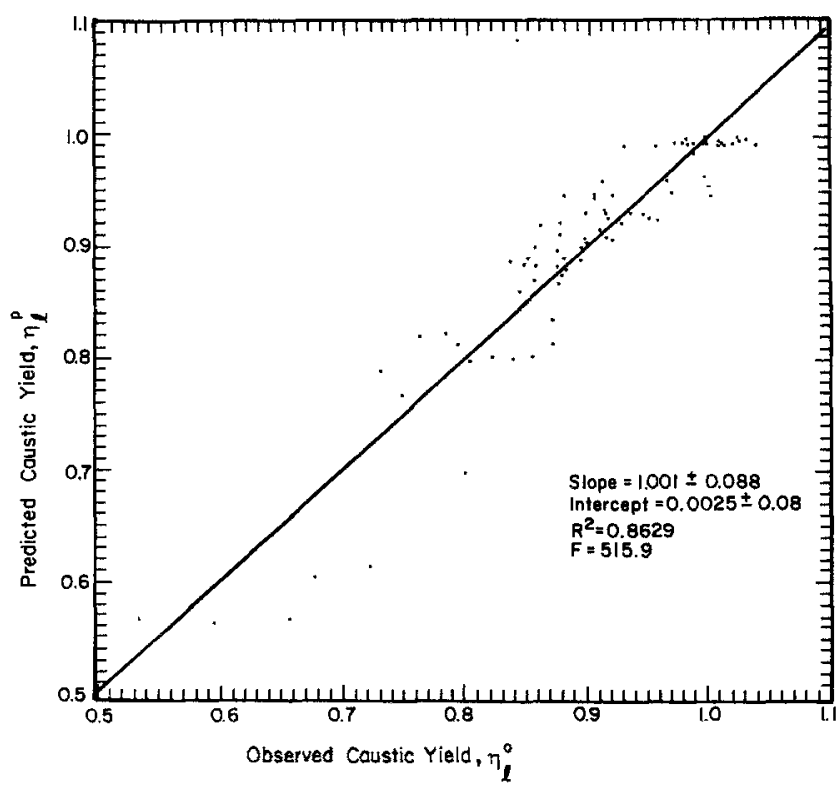

Fig. 3. Comparison of model predictions and experimental caustic yield data from Ref. (11) using the LS parameters of case C, Table I. bles. Figures 5 and 6 show that the residuals (i.e., the difference between the predicted and observed values) are independent of the dependent variables as required by LS regression theory $(2,3,27)$. Similar plots of the residuals and effective thickness $\left(N_{M} t\right)$, current density, and velocity indicate no correlation between these independent variables and residuals (26). Thus, it can be concluded that the model with the LS parameter estimates of case C in Table I can be used to predict both the caustic yield and the diaphragm voltage drop.

Also, if the diaphragm effective thickness, $N_{\mathrm{M}} t$, was known to change with time (due to plugging. of the diaphragm, for example), the model could be adapted for interpolation purposes by minimizing Eq. [42] by adjusting $N_{\mathrm{M}} t$ with the values of $D_{1}$ and $\kappa_{\text {avg }}$ held constant at the specified values of case C. This adjusting of $N_{\mathrm{M}} t$ was not necessary for the experimental data used here because both the values of $N_{\mathrm{M}}$ and $t$ were not significantly different before and after the experiments (11).

Electrode kinetics.-Calculation of the cell voltage, $V_{\mathrm{T}}$, by Eq. [18] requires knowledge of the kinetic parameters corresponding to the Tafel equations for the anode and

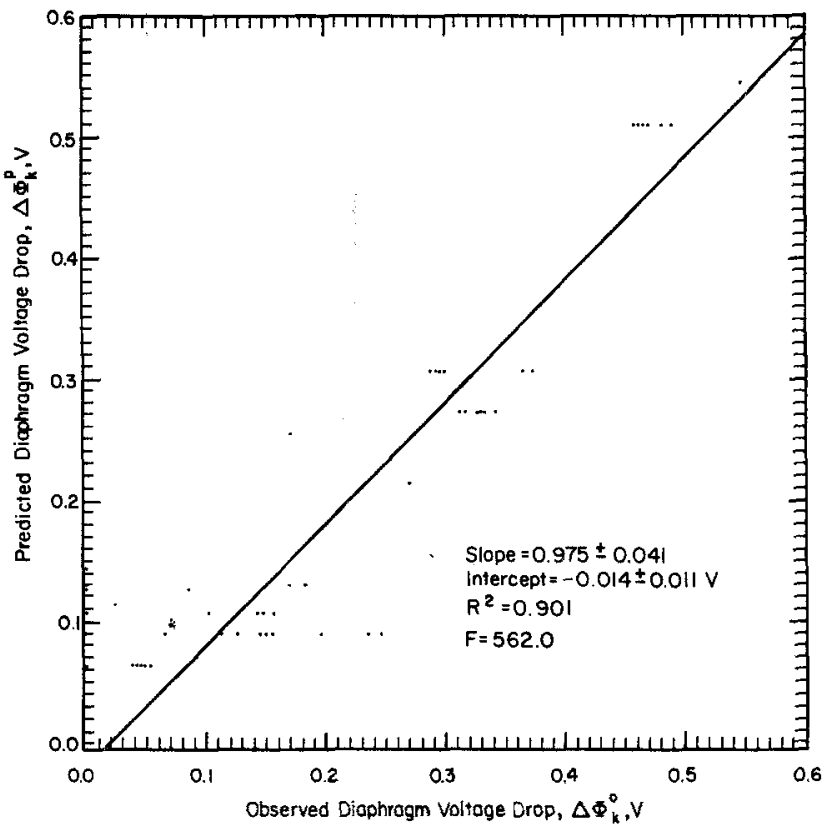

Fig. 4. Comparison of model predictions and experimental diaphragm voltage-drop data from Ref. (11) using LS parameters of case C, Table I. 


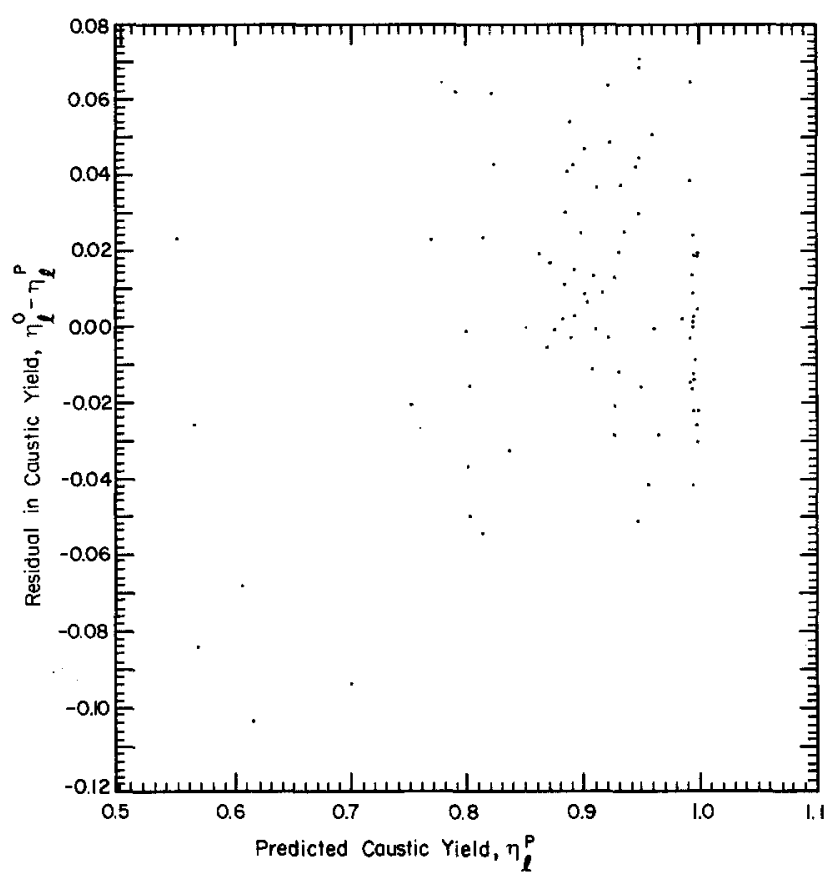

Fig. 5. Dependence of residuals on caustic yield predictions using LS parameters of case $\mathrm{C}$, Table 1 .

cathode. The kinetic data obtained in Ref. (11) are proprietary, but for purposes of illustration, the data of Caldwell (28) can be used to estimate these kinetic parameters. That is, Caldwell reports hydrogen and chlorine overpotentials as functions of temperature and current density. By assuming that these overpotentials are independent of $\mathrm{NaOH}$ and $\mathrm{NaCl}$ concentrations, estimates of $\alpha_{i}$ and $i_{0, i}$ can be obtained by LS for use in Eq. [18] and then in Eq. [17] for prediction of the specific energy cost.

Since the overpotential data for hydrogen on lowcarbon steel in $2.5 \mathrm{M} \mathrm{NaOH} / 3.01 M \mathrm{NaCl}$ electrolyte are large negative numbers, the Butler-Volmer expression can be inverted to give an explicit expression for $V_{1}$, the dependent variable

$$
V_{1}=\frac{R T}{\alpha_{1} \mathbf{F}} \ln \left(i_{0,1}\right)-\frac{R T}{\alpha_{1} \mathbf{F}} \ln i
$$

Thus an appropriate objective function for this data is

$$
H_{1}\left(\alpha_{1}, i_{0,1}\right)=\sum_{\mathrm{l}=1}^{\mathrm{N}}\left(V_{1,1}{ }^{\mathrm{o}}-V_{1,1}^{\mathrm{p}}\right)^{2}
$$

Equation [44] can be minimized easily with a hand calculator or statistical subroutines $(25,26)$. Unfortunately, the residuals of Eq. [44] exhibit a large correlation with temperature when all of the data (28) are used to estimate the parameters (26). Consequently, the parameter esti-

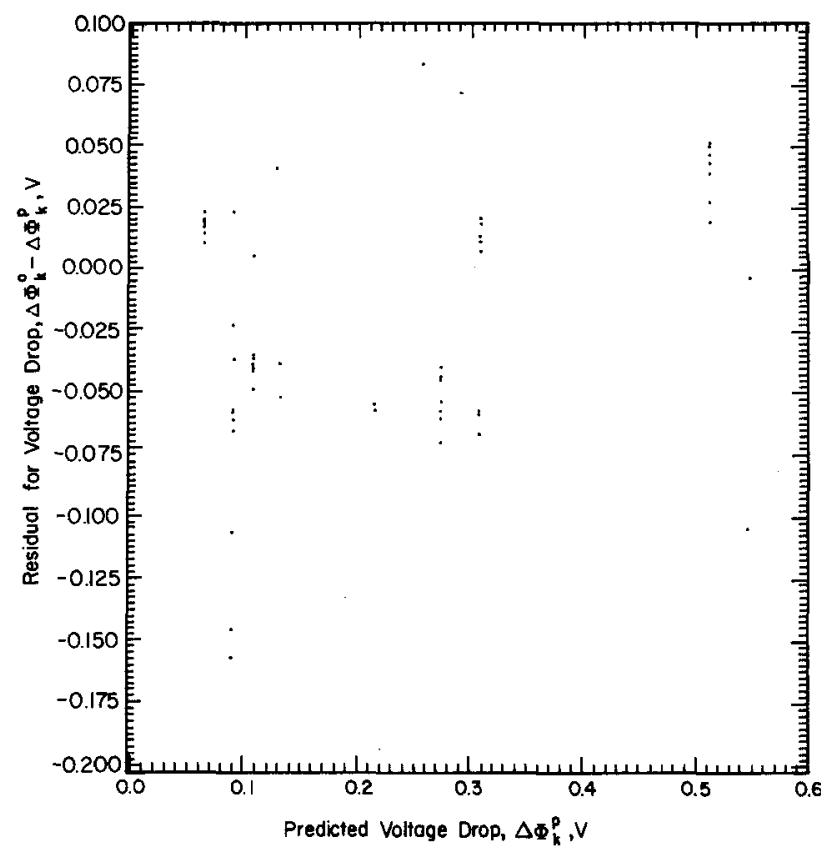

Fig. 6. Dependence of residuals on diaphragm voltage-drop predictions using LS parameters of case C, Table I.

mates ( $\alpha_{1}$ and $i_{0,1}$ ) were determined using only the data (28) for $343 \mathrm{~K}$ (i.e., $N=5$ ) as shown in Table II. The confidence intervals on $i_{0,1}$ and $\alpha_{1}$ are small, even though the number of data points is small. It should be noted that even though the determination of values for $\alpha_{1}$ and $i_{0,1}$ is simple, the determination of their confidence intervals is complicated because the Tafel equation confidence intervals correspond to $1 / \alpha_{1}$ and $\left[\ln \left(i_{0,1}\right)\right] / \alpha_{1}$. The confidence intervals of Table II were determined from nonlinear regression routines (26). Figure 7 compares the predictions of Eq. [43] with the data of Caldwell (28). Residual plots (26) did not show a correlation of predicted overpotentials with current density.

The overpotential data for production of chlorine on $\mathrm{RuO}_{2}-\mathrm{TiO}_{2}$ on titanium (28) should not be analyzed with a Tafel expression similar to Eq. [43] because the cathodic part of the Butler-Volmer expression is significant at small overpotentials. Instead, an implicit calculation should be performed to determine the dependent variable $V_{2}$. This calculation is performed by forming the function, $f_{1}$

$$
f_{1, \mathrm{I}}=0=i_{2,1}-i_{0,2}\left\{\exp \left(\frac{\alpha_{2} \mathbf{F}}{R T_{1}} V_{2,1}\right)-\exp \left[\frac{\left(\alpha_{2}-2\right)}{R T_{1}} \mathbf{F} V_{2,1}\right]\right\}
$$

Then for the given independent variables, $i_{2,1}$ and $T_{1}$, and assumed values of $\alpha_{2}$ and $i_{0,2}$, values of $V_{2,1}$ can be deter-

\begin{tabular}{|c|c|c|c|c|c|}
\hline \multicolumn{6}{|c|}{ Case A. Hydrogen on low-carbon steel in $2.5 \mathrm{M} \mathrm{NaOH}$ and $3.01 \mathrm{M} \mathrm{NaCl}$ electrolyte at $343.15 \mathrm{~K}$} \\
\hline Parameter & Estimate & \pm & $\begin{array}{l}\text { 95\% Confidence } \\
\text { Interval }\end{array}$ & Units & ${ }_{t \text {-statistic }}^{\mathrm{h}}$ \\
\hline $\begin{array}{l}\alpha_{1} \\
i_{0,1}\end{array}$ & $\begin{array}{l}0.5723 \\
4.085 \times 10^{-4}\end{array}$ & \pm & $\begin{array}{l}0.0153 \\
0.490 \times 10^{-4}\end{array}$ & $\begin{array}{c}\text { none } \\
\mathrm{A} / \mathrm{cm}^{2}\end{array}$ & $\begin{array}{r}119.0 \\
26.5\end{array}$ \\
\hline \multicolumn{6}{|c|}{ Case B. Chlorine on $\mathrm{RuO}_{2}-\mathrm{TiO}_{2}$ on titanium in $5.02 \mathrm{M} \mathrm{NaCl}$ determined using Eq. [45] and [46] } \\
\hline Parameter & Estimate & \pm & $\begin{array}{l}\text { 95\% Confidence } \\
\text { interval }\end{array}$ & Units & $\begin{array}{c}\mathrm{b} \\
t \text {-ștatistic }\end{array}$ \\
\hline $\begin{array}{l}\alpha_{2} \\
i_{0,2}\end{array}$ & $\begin{array}{l}1.809 \\
3.710 \times 10^{-3}\end{array}$ & $\begin{array}{l} \pm \\
\pm\end{array}$ & $\begin{array}{l}0.592 \\
3.097 \times 10^{-3}\end{array}$ & $\begin{array}{l}\text { none } \\
\mathrm{A} / \mathrm{cm}^{2}\end{array}$ & $\begin{array}{l}6.3 \\
2.5\end{array}$ \\
\hline
\end{tabular}
mined (by Newton's method, for example) such that $f_{1,1}$ is

Table II. Kinetic parameter estimates ${ }^{\mathrm{a}}$

${ }^{a}$ Based on data presented by Caldwell (28).

"See Ref. (26). 


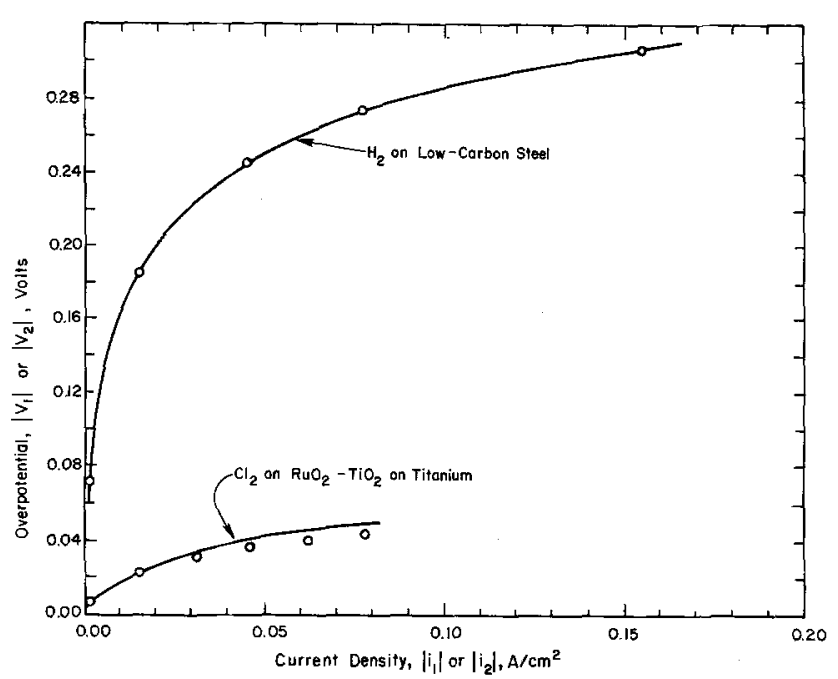

Fig. 7. Comporison of hydrogen overpotential predictions and data of Ref. (28), and comparison of chlorine overpotential data of Ref. (28) and predictions from Eq. [45] and LS parameters of case B, Table II, at $343.15 \mathrm{~K}$.

approximately zero. The assumed values of $\alpha_{2}$ and $i_{0,2}$ can be adjusted to obtain a minimized objective function which can be defined

$$
H_{2}\left(\alpha_{2}, i_{0,2}\right)=\sum_{\mathrm{l}=1}^{24}\left(V_{2,1}^{\mathrm{o}}-V_{2,1}^{\mathrm{p}}\right)^{2}
$$

Nonlinear regression techniques (26) must be used to minimize Eq. [46]. It should be noted that Eq. [45] assumes that the apparent transfer coefficients sum to the number of electrons evolved in the overall oxidation of choride to chlorine (two here).

The estimated parameters using this implicit formulation for the chlorine reaction are shown in case B of Table II. The confidence intervals for these parameters are large, which indicates the need for more data at larger current densities. Figure 7 compares the experimental and predicted values at these parameter estimates. Residual plots (26) did not indicate significant correlations of the residuals with either current density or temperature, and, therefore, all of the data reported by Caldwell (28) was used.

\section{Electrical Energy Cost Predictions}

The specific electrolyzer energy cost for $\mathrm{NaOH}$ production (i.e., Eq. [17]) can be predicted with confidence for the range of industrial conditions covered by the factorial experiment by using the parameter estimates of Tables I and II. An example of these energy cost predictions is shown in Fig. 8. The physical properties and parameters used for the calculations are shown in Table III. It should

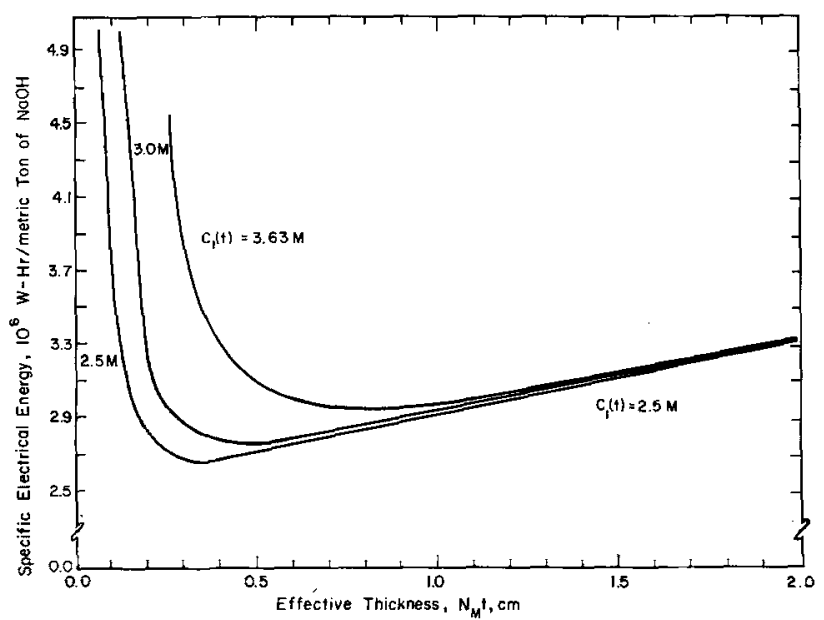

Fig. 8. Electrical energy cost predictions for $\mathrm{NaOH}$ production
Table III. Physical parameters for minimum energy calculation

$$
\begin{array}{ll}
D_{1} & =2.826 \times 10^{-5} \mathrm{~cm}^{2} / \mathrm{s} \\
i & =0.200 \mathrm{~A} / \mathrm{cm}^{2} \\
i_{0,2} & =3.710 \times 10^{-3} \mathrm{~A} / \mathrm{cm}^{2} \\
i_{0,1} & =4.085 \times 10^{-4} \mathrm{~A} / \mathrm{cm}^{2} \\
s & =0.635 \mathrm{~cm} \\
T & =343.15 \mathrm{~K} \\
\alpha_{1} & =0.5723 \\
\alpha_{2} & =1.809 \\
\left|\Delta U^{\theta}\right| & =2.188 \mathrm{~V} \\
\epsilon_{\mathrm{b}} & =0.5 \\
\kappa_{\text {anolyte }}{ }^{2} & =0.491 \Omega^{-1} \mathrm{~cm}^{-1} \\
\kappa_{\text {avg }} & =0.338 \Omega^{-1} \mathrm{~cm}^{-1}
\end{array}
$$

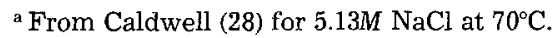

be noted that the only assumed value in Table III is the void fraction of bubbles in the anolyte; all other values correspond to either parameter estimates, physically measurable properties (i.e., diaphragm, electrolyte, or cell geometry properties), or operating conditions. Consideration of Fig. 8 shows that an $N_{\mathrm{M}} t$ can be selected which minimizes the specific electrical energy cost for $\mathrm{NaOH}$ production at a specified current density and caustic effluent concentration (or effluent velocity as shown in Fig. 9). However, it is important to note that this minimum occurs at a value of $N_{\mathrm{M}} t$ beyond that used in the experimental work and may, consequently, be invalid.

\section{Conclusion}

Development of a simple model of the diaphragm in terms of measurable diaphragm properties has provided a design equation which allows direct comparison of experimental data and theoretical predictions. This comparison, accomplished with parameter estimation techniques, shows that the models of the caustic yield and the voltage drop through the diaphragm are reasonable; changing the assumption of a linear potential gradient through the diaphragm may provide an improvement. The parameter estimates and the simple model provide a design equation which can be used to predict the minimum specific electrical energy required for $\mathrm{NaOH}$ production as a function of the effective thickness, $N_{\mathrm{M}} t$, the current density, and the caustic concentration in the effluent (or the effluent velocity).

\section{Acknowledgments}

The authors acknowledge gratefully the support of this work by the Dow Chemical Company and the comments and suggestions by Mr. Donald L. Caldwell.

Manuscript submitted April 30, 1984; revised manuscript received Dec. 27, 1984.

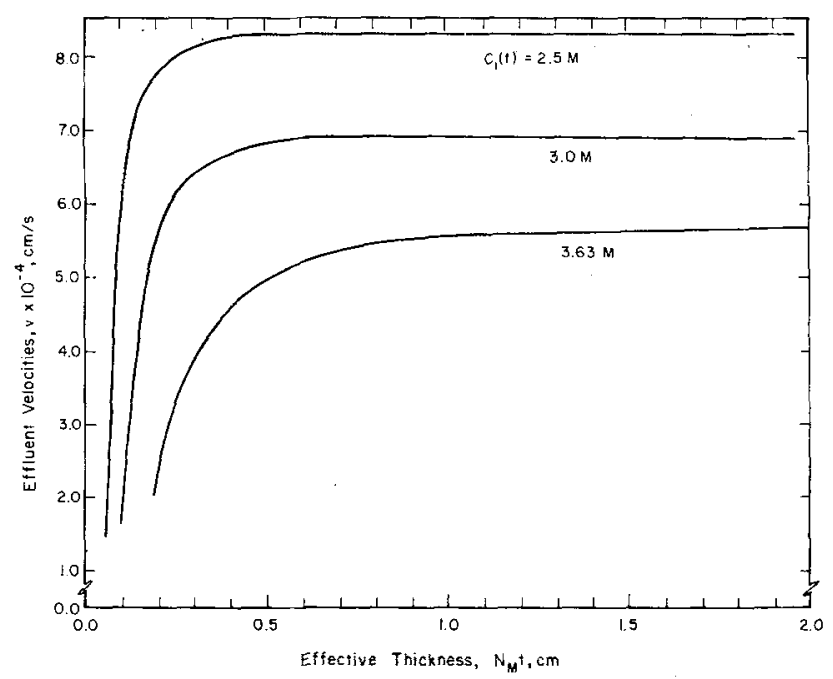

Fig. 9. Effluent velocities corresponding to energy cost predictions of Fig. 8. 


\section{LIST OF SYMBOLS}

\section{$A_{1} \quad$ see Eq. [13] $\left(\mathrm{cm}^{-1}\right)$}

$A_{\mathrm{d}} \quad$ area of diaphragm $\left(\mathrm{cm}^{2}\right)$

$A_{\mathrm{p}} \quad$ area of pores within the diaphragm $\left(\mathrm{cm}^{2}\right)$

$\mathrm{C}_{1}, \mathrm{C}_{1}(x)$ position dependent concentration of $\mathrm{OH}^{-}$ ion $\left(\mathrm{mol} / \mathrm{cm}^{3}\right)$

$C_{1}(x=t), C(t)$ concentration of $\mathrm{OH}^{-}$ion at

diaphragm/catholyte interface $\left(\mathrm{mol} / \mathrm{cm}^{3}\right)$

$\mathrm{C}_{1, \text { effuent }} \quad$ concentration of $\mathrm{OH}^{-}$ion in catholyte effluent $\left(\mathrm{mol} / \mathrm{cm}^{3}\right)$

$\mathrm{CE} \quad$ cost of electrical energy $(\$ / J)$

$D_{1} \quad$ free stream diffusion coefficient of $\mathrm{OH}^{-}$ ion $\left(\mathrm{cm}^{2} / \mathrm{s}\right)$

$D_{e} \quad$ effective diffusion caefficient of $\mathrm{OH}^{-}$ion

$E C_{\text {el }} \quad\left(\mathrm{cm}^{2} / \mathrm{s}\right)$ specific electrical energy cost for $\mathrm{NaOH}$

production $(\$ / g)$

EL length parameter (see Eq. [28]) $(\mathrm{cm})$

F Faraday's constant $(96,487 \mathrm{C} / \mathrm{mol})$

$F_{1}$ feed concentration of $\mathrm{NaCl}\left(\mathrm{mol} / \mathrm{cm}^{3}\right)$

$f_{1,1} \quad$ functional representation of Butler-Volmer equation equal to zero at $l$ th datum (see Eq. [45])

$G(\beta)$ least squares objective function with parameter vector $\beta$, see $\mathrm{Eq}$. [42]

$H_{1}, H_{2} \quad$ least squares objective function for hydrogen and chlorine electrode kinetics, respectively, see Eq. [44] and [46]

$i$

$i_{2,1}$

$i_{0,1}, i_{9,2}$

$\stackrel{l}{M}$

$M_{1}$

N

$N_{1}$

$N_{\mathrm{M}}$

$N_{\mathrm{H}}$

$n_{1}$
$\mathrm{Pe}$

$R$

$s$

$T$

$t$

$t_{j}, t_{1}$

$u_{j}, u_{1}$

$U$

$\Delta U^{\theta}$

$V_{\mathrm{T}}$

$V_{1}^{\mathrm{T}}, V_{2}$

$V_{1,1^{0}}, V_{2,1^{0}}$

$V_{1,1^{p}}, V_{2,1}{ }^{p}$

$v$

$x$

$z_{j}, z_{1}$

$\alpha_{1}, \alpha_{2}$

$\frac{\beta}{\delta}$

$\epsilon$

$E_{\mathrm{b}}$

$\eta$

$\kappa_{\text {avg }}$ current density through the diaphragm $\left(\mathrm{A} / \mathrm{cm}^{2}\right)$

current density on anode corresponding to Ith datum $\left(\mathrm{A} / \mathrm{cm}^{2}\right)$

exchange current density of hydrogen and chlorine electrodes, respectively $\left(\mathrm{A} / \mathrm{cm}^{2}\right)$ average pore length, see Eq. [29] (cm) number of data points for diaphragm voltage drop

molecular weight of $\mathrm{NaOH}(39.99 \mathrm{~g} / \mathrm{mol})$

number of data points for caustic yield or

flux of $\mathrm{OH}^{-}$ion in diaphragm $\left(\mathrm{mol} / \mathrm{cm}^{2} \mathrm{~s}\right)$

MacMullin number, see Eq. [2], dimensionIess

Hine number, see Eq. [23], dimensionless

transference number of $\mathrm{OH}-$ ion $\left(\mathrm{cm}^{3} / \mathrm{mol}\right)$

Peclet number, see Eq. [20], dimensionless gas constant (8.3143 J/mol K)

distance between anode and diaphragm anolyte face $(\mathrm{cm})$

temperature $(\mathrm{K})$

diaphragm thickness $(\mathrm{cm})$

transport number of species $j, j=1$ for $\mathrm{OH}-$ ion

mobility of species $\mathrm{j}, \mathrm{j}=1$ for $\mathrm{OH}^{-}$ion $\left(\mathrm{cm}^{2}-\mathrm{mol} / \mathrm{J}-\mathrm{s}\right)$

relative velocity expression of Stender et al. (6) $(\mathrm{cm} / \mathrm{s})$ cell $(2.188 \mathrm{~V})$

total cell voltage, see $\mathbf{E q} .[18](\mathrm{V})$

hydrogen and chlorine overpotential, respectively (V)

observed hydrogen and chlorine kinetic overpotential, respectively, at $l$ th datum predicted hydrogen and chlorine kinetic overpotential, respectively, at independent variables corresponding to $l$ th datum percolation velocity through the diaphragm $(\mathrm{cm} / \mathrm{s})$

diaphragm dimensional coordinate $(\mathrm{cm})$

ionic charge for species $\mathrm{j}, \mathrm{j}=1$ for $\mathrm{OH}$-ion

\section{Greek}

apparent transfer coefficients for hydrogen and chlorine reactions, respectively vector of parameters for $\operatorname{LS}\left(\beta=\left[D_{1} \kappa_{\mathrm{avg}}\right]^{\mathrm{T}}\right)$ diaphragm effective thickness, see $\mathrm{Eq}$. [24] (cm)

porosity of diaphragm, dimensionless

void fraction of gas bubbles in anolyte, dimensionless

caustic yield, dimensionless

average specific conductivity of electrohydrogen overpotential

open-circuit potential for chlorine/caustic lyte in the diaphragm $\left(\Omega^{-1} \mathrm{~cm}^{-1}\right)$

*anolyte specific conductivity of anolyte $\left(\Omega^{-1} \mathrm{~cm}^{-1}\right)$

$\Phi(x), \Phi$

$\Delta \Phi$ dimensional voltage drop through the diaphragm (V)

dimensionless voltage drop through the diaphragm

resistivity of diaphragm filled with electrolyte $(\Omega \mathrm{cm})$

resistivity of electrolyte with an equivalent

$\begin{array}{ll}\rho_{0} & \text { thickness of the diaphragm }(\Omega \mathrm{cm}) \\ \hat{\sigma}_{1}{ }^{2} & \text { estimated variance of caustic yield, dimen }\end{array}$ sionless

$\hat{\sigma}_{2}{ }^{2} \quad$ estimated variance of diaphragm voltage drop $\left(\mathrm{V}^{2}\right)$

$\tau \quad$ tortuosity of diaphragm, dimensionless

$\theta_{1}(\zeta)$ dimensionless concentration of $\mathrm{OH}^{-}$ion at $\zeta$ dimensionless coordinate $(\zeta=x / t)$

\section{REFERENCES}

1. R. J. Freund and P. D. Minton, "Regression Methods," p. 25, Marcel Dekker, Inc., New York (1979).

2. B. Ostle and R. W. Mensing, "Statistics in Research," 3rd ed., pp. 166-178, Iowa State University Press, Ames, IA (1975).

3. A. R. Gallant, Am. Stat., 29, 73 (1975).

4. A. R. Gallant and D. W. Jorgenson, J. Econometrics, 11, 275 (1979).

5. J. Lee, "Identification and Estimation of Model Parameter in Electrochemical Reactor Design," Presented at AIChE Meeting, Denver, Co, August 1983.

6. V. V. Stender, O. S. Ksenzhek, and V. N. Lazarev, Zh. Prikl. Khim., 40, 1293 (1967).

7. T. Mukaibo, J, Electrochem. Soc. Jpn., 20, 482 (1952).

8. P. Gallone and E. Rubino, Ann. Chim., 66, 103 (1976).

9. W. H. Koh, AIChE Symp. Ser., \%7, 213 (1981).

10. W. H. Koh, Paper 391 presented at The Electrochemical Society Meeting, St. Louis, MO, May 11-16, 1980.

11. K. A. Poush, D. L. Caldwell, J. W. Van Zee, and R. E. White, in "Modern Chlor-Alkali Technology," Vol. 2, C. Jackson, Editor, Ellis Horwood Limited, Chichester, West Sussex, England (1983).

12. D. L. Caldwell, K. A. Poush, J. W. Van Zee, and R. E. White, in "Electrochemical Process and Plant Design," R. C. Alkire, T. R. Beck, and R. D. Varjian, Editor, p. 216, The Electrochemical Society Softbound Proceedings Series, Pennington, NJ (1983).

13. R. B. MacMullin and G. A. Muccini, AIChE J., 2, 393 (1956).

14. F. Hine, M. Yasuda, and K. Fujita, This Journal, 128, 2314 (1981).

15. L. G. Austin, "Handbook of Fuel Cell Technology," p. 160, Prentice-Hall, Inc., Englewood Cliffs, NJ (1968).

16. F. Hine, M. Yasuda, and T. Tanaka, Electrochim. Acta, 22, 429 (1977).

17. F. Hine, Soda To Enso, 219 (1980).

18. R. R. Chandran and D-T. Chin, Paper 562 presented at The Electrochemical Society Meeting, San Francisco, CA May 8-13, 1983.

19. V. L. Kubasov, V. B. Vorbena, and L. I. Yurkov, Sov. Electrochem., 15, 1773 (1979).

20. J. S. Newman, "Electrochemical Systems," PrenticeHall, Inc, Englewood Cliffs, NJ (1973).

21. D. A. G. Bruggeman, Ann. Phys., 24, 636 (1935).

22. R. E. De La Rue and C. W. Tobias, This Journal, 106, 827 (1959).

23. R. E. White, J. S. Beckerdite, and J. Van Zee, in "Electrochemical Cell Design," R. E. White, Editor, Plenum Press, NY (1984).

24. F. Hine and M. Yasuda, This Journal, 118, 116 (1971).

25. International Mathematical and Statistical Library subroutines ZXSSQ and ZXMIN, IMSL, Inc., Houston, TX.

26. J. W. Van Zee, Ph.D. Dissertation, Texas A\&M University, College Station, TX (1984).

27. N. Draper and H. Smith, "Applied Regression Analysis," 2nd ed., pp. 108-112, John Wiley and Sons, Inc., NY (1981).

28. D. L. Caldwell, in "Comprehensive Treatise of Electrochemistry," Vol. 2, J. O'M. Bockris, B. E. Conway, E. Yeager, and R. E. White, Editors, pp. 121-129, Plenum Press, NY (1981). 